\title{
A VIRAVOLTA MACHADIANA: VELHO PROBLEMA, NOVA QUESTÃO. RESENHA DE MACHADO DE ASSIS - POR UMA POÉTICA DA EMULAÇÃO, DE JOÃO CEZAR DE CASTRO ROCHA
}

\section{THE MACHADIAN TURN ABOUT: OLD PROBLEM, NEW QUESTION. REVIEW OF MACHADO DE ASSIS - POR UMA POÉTICA DA EMULAÇÃO, DE JOÃO CEZAR DE CASTRO ROCHA}

ROCHA, João Cezar de Castro. Machado de Assis - por uma poética da emulação. Rio de Janeiro: Civilização Brasileira, 2013. 368p.

Antonio Marcos Vieira Sanseverino

Universidade Federal do Rio Grande do Sul

Porto Alegre, RS, Brasil

Um dos enigmas literários é a viravolta que Machado de Assis impõe a sua obra a partir de Memórias póstumas de Brás Cubas. Não se trata apenas da diferença em relação aos primeiros quatro romances, trata-se da construção de uma obra-prima a partir de um salto qualitativo. Essa mudança foi explicada por Roberto Schwarz a partir da alteração do ponto de vista ideológico, em que Machado abandona a ideologia paternalista e ao mesmo tempo adota o ponto de vista da elite, através de Brás Cubas. Schwarz mostra que "o social está na forma", a partir de um método em que "o ponto de partida está na configuração da obra, com as luzes que lhe são próprias, e não na sociedade". ${ }^{2}$ Analisando a ordem shandiana do romance moderno, Sergio Paulo Rouanet $^{2}$ faz um estudo de conjunto de Sterne, Diderot, Xavier de Maistre, Almeida Garret e Machado de Assis. Identifica uma linhagem comum (explicitada pelo próprio Machado) em que há uma base comum (a forma livre e difusa). De modo semelhante, a partir do vínculo a uma linhagem temos a leitura de Enylton Sá Rego, ${ }^{3}$ que mostra a produtividade da tradição da sátira menipeia. Em outra hipótese de leitura, Sônia

\footnotetext{
${ }^{1}$ SCHWARZ, Roberto. Um mestre na periferia do capitalismo: Machado de Assis. São Paulo: Duas Cidades, 1990. p. 188.

${ }^{2}$ ROUANET, Sergio Paulo. Riso e melancolia: a forma shandiana em Sterne, Diderot, Xavier de Maistre, Almeida Garret e Machado de Assis. São Paulo: Companhia das Letras, 2007.

${ }^{3}$ REGO, José Enylton de Sá. O calundu e a panaceia: Machado de Assis, a sátira menipeia e a tradição luciânica. Rio de Janeiro: Forense Universitária, 1989.
} 
Brayner põe relevo ao exercício regular da crônica. O contato com o leitor do jornal e o recurso da oralidade (informalidade do narrador) forneceram "o desembaraço preparatório para as experiências de um novo enunciado romanesco". 4

João César de Castro Rocha, em Machado de Assis - por uma poética da emulação, debruça-se mais uma vez sobre o enigma da viravolta machadiana. Seu esforço ambicioso é "desenhar um novo retrato de Machado de Assis". 5 Sua hipótese de leitura se volta para o impacto que a publicação de $O$ primo Basílio (1878) teve sobre a literatura brasileira e especificamente a reação de Machado de Assis, que se viu forçado a "tudo arriscar na fatura de Memórias póstumas de Brás Cubas" (p. 20).

Retomo a hipótese esboçada na introdução: a ruptura conheceu um evento-ponte em fevereiro de 1878. Não digo que se trate de causa determinante, muito menos de fator único, penso antes num efeito catalisador, que permitiu ao autor de Iaiá Garcia superar-se, reinventando sua literatura. (p. 86)

Note-se que a publicação de $O$ primo Basílio é vista como "evento-ponte", e como "efeito catalisador". Cabe destacar que a relação de Machado de Assis e Eça de Queiroz seria de emulação, em que o autor brasileiro percebe a necessidade de compreender e superar o romance de Eça. O procedimento, próprio da poética clássica, é anacronicamente posto em ação, coloca a centralidade da incorporação do modelo, a leitura das obras anteriores e a produção de uma novidade pelo desvio. $\mathrm{O}$ valor romântico da originalidade, de uma criação ex-nihilo, é posto de lado, para um tratamento paródico da tradição. E nessa tradição entra de modo incontornável o romance de Eça de Queiroz, grande sucesso em Portugal e no Brasil.

Castro Rocha não se fixa, no entanto, no diálogo direto entre $O$ primo Basílio e Memórias póstumas de Brás Cubas. Faz o cruzamento de diversos gêneros produzidos por Machado de Assis. Vai da crônica ao romance, passando pela leitura de contos,

\footnotetext{
4 BRAYNER, Sônia. Metamorfoses machadianas: laboratório ficcional. In: BOSI, Alfredo et al. Machado de Assis. (Grandes escritores 1). São Paulo: Ática, 1982. p. 426.

${ }^{5}$ ROCHA, João Cezar de Castro. Machado de Assis - por uma poética da emulação. Rio de Janeiro: Civilização Brasileira, 2013. p. 32. Daqui para frente, para facilitar a leitura, será apenas referida a página de onde foi tirada a citação.
} 
poemas e crítica literária. Rastreia a sedimentação da emulação como procedimento básico da escrita machadiana. Para caracterizar a mudança, no primeiro capítulo, faz comparação entre as fases, a partir da leitura dos finais, dos quatro primeiros romances. "Nada escapa ao olhar do narrador dessa primeira fase. Ao leitor resta apenas o direito de admirar sua onisciência" (p. 49). Por sua vez, na dita segunda fase,

Já os narradores e as personagens posteriores à invenção de Brás Cubas parecem perder progressivamente o controle da interpretação, antecipando o processo que idealmente deve ocorrer com o próprio leitor, em virtude da complexidade crescente dos recursos machadianos. (p. 59, grifo meu)

Na perda do "controle da interpretação", Castro Rocha coloca o núcleo da mudança da poética machadiana a partir das Memórias póstumas. Trata-se de um afastamento de um modelo narrativo bem-comportado para uma estética aberta, que incorpora o leitor para obrigá-lo a atuar na construção de hipóteses interpretativas.

No segundo capítulo, "No meio do caminho tinha um autor", retoma o sucesso do lançamento de $O$ primo Basílio, em 1878, e a crítica machadiana. Ao primeiro texto, seguiram-se algumas respostas a Machado de Assis, que publica um segundo texto. No rebate, quando Machado retoma a repercussão, as respostas ao seu artigo, ele mostra o impasse entre Romantismo e Realismo, a ser desdobrado depois em A nova geração (1879). As obras e os autores recuperados como referência (Alexandre Herculano, Gonçalves Dias, José de Alencar) não o foram por serem românticos ou clássicos, mas por fazerem parte de uma tradição com a qual se dialoga.

Creio que seria interessante ponderar o juízo de Castro Rocha sobre o texto crítico de Machado: "pelo contrário, são suas páginas menos felizes" (p. 94). Machado de Assis escreve crítica contundente, com os limites do momento, mas ainda assim de qualidade. Concentra-se em $O$ primo Basílio para criticar a falta de verdade no conflito da personagem Luísa. Ela se entrega ao adultério com seu antigo namorado, o primo Basílio, por inclinação. Perto da volta de viagem do marido, ela e o amante estão entediados, terminando a relação. Segundo Machado, o romance terminaria aí, na volta do marido, porque Luísa propenderia a se acomodar no seu casamento, mas Eça 
aumenta a extensão criando o roubo das cartas por Juliana, empregada com desejo de enriquecer. Seria falta de verdade, porque o enredo na arte (diferente de uma simples anedota ou notícia de jornal) deve partir da natureza da personagem, de seu conflito moral. A mesma falta de organicidade, Machado aponta nas adjetivações exageradas e nas descrições minuciosas (apenas inventários) com que Eça se desviaria do essencial para ficar preso ao acessório.

Nessa crítica, há um modelo de romance subjacente. Não há ideal de prosa romanesca, mas está posto um problema que pode servir de referência para a compreensão das Memórias póstumas. O autor coloca-se entre os exageros da escola romântica (olhar com os olhos da alma, com os excessos da imaginação) e os da escola realista (fixar-se na sensação imediata das coisas), a fim de preservar a verdade estética. Desse modo, Machado, enquanto crítico, não se volta contra padrões românticos ou naturalistas, mas se posiciona contra processos compositivos cristalizados. Estes se tornam regras escolares, fazendo com que os autores esqueçam o real para se prenderem a traços estilísticos desprovidos de sentido. Em termos romanescos, o crítico censura Eça de Queiroz por descer a detalhes escabrosos que não contribuem para a totalidade do romance e que apenas denunciam sua filiação ao Realismo de Zola. A intriga do romance seria tão frágil, que desmoronaria se Juliana não tivesse roubado as cartas de Luísa. Quer dizer, o conflito não seria expressão do sujeito, mas exterior a esse:

Não peço, decerto, os estafados retratos do Romantismo decadente; pelo contrário, alguma coisa há no Realismo que pode ser colhido em proveito da imaginação e da arte, mas sair de um excesso para cair em outro, não é regenerar nada: é trocar o agente da corrupção. [...]

Resta-me concluir, e concluir aconselhando aos jovens talentos de ambas as terras de nossa língua, que não se deixem seduzir por uma doutrina caduca, embora no verdor dos anos. Este messianismo literário não tem a força da universalidade nem da vitalidade; traz consigo a decrepitude. Influi, decerto, em bom sentido e até certo ponto, não para substituir as doutrinas aceitas, mas corrigir o excesso de sua aplicação. nada mais. Voltemos os olhos para a realidade, mas excluamos o Realismo, assim não sacrificaremos a verdade estética. ${ }^{6}$

\footnotetext{
${ }^{6}$ ASSIS, Machado de. Obras completas. v. 3. Rio de Janeiro: Nova Aguilar, 1994. p. 913.
} 
A conclusão de Machado de Assis impressiona pela defesa da independência do artista. Trocar Romantismo por Realismo não é mudança substancial, pois em ambos os casos o artista não observa a realidade diretamente, mas vê apenas o que é previsto pela doutrina literária e constrói o texto a partir de um molde pré-estabelecido. É possível retirar dessa citação pelo menos uma constante machadiana: a necessidade da verossimilhança como marca da verdade estética. Daí decorre o desligamento da moda literária vigente, pois o artista não deve se preocupar em ser fiel a um modelo estético, mas antes em construir uma obra coerente e verossímil, capaz de representar um conflito humano possível.

Há como princípio a necessidade de se observar a natureza humana. Não se trata de cobrança de nacionalismo, de expressão de símbolos consagrados como a natureza e o índio enquanto traços da cor local brasileira. A observação e análise desejadas dizem respeito à composição do caráter humano, na convivência social, em que se cristalizam os hábitos em uma segunda natureza.

A recuperação da crítica machadiana é importante, pois Castro Rocha levanta como hipótese que "o leitor de $O$ primo Basílio foi o autor de Iaiá Garcia e não o criador de Memórias póstumas de Brás Cubas" (p. 109). O ponto de partida é de que Machado, autor das Memórias, não se confundiria com Machadinho, leitor de Eça. Vale ler um trecho para comentá-lo:

Posso, agora, rematar minha hipótese: o Machadinho de 1878, isto é, o leitor de $O$ primo Basílio, certamente condenaria o Machado de 1880, [...]. Para o crítico moralista de 1878, as aventuras de Brás Cubas pareceriam desnecessariamente eróticas: o móvel de sua ação pouco definido; sobretudo o crítico normativo de 1878 rejeitaria a falta de verossimilhança de um defunto narrador. Isso para não mencionar a falha fundamental de estrutura: ora, como principiar uma história pela conclusão? Ainda: como deixar de condenar um romance em que o acessório parece sempre impor-se ao essencial, através da técnica da digressão, com inegável sabor sterniano? Sem dúvida, MachadoBoileau consideraria as Memórias póstumas de Brás Cubas um romance indecoroso e pobremente construído. (p. 122, grifo meu)

Há um interessante exercício de suposição de como o Machado logo anterior à virada leria as Memórias póstumas. O nó do problema, creio eu, está posto na suposição 
de uma mudança da água para o óleo. No caso de Machado, o ano de 1878 é um momento de crise. Os fundamentos da crítica a Eça, bem como de A nova geração, deixam transparecer o interesse de ler, sem concessão, a produção literária que se legitima no campo literário dos anos 70. Na observação do trânsito do Romantismo para o Realismo, Machado anota a tendência de filiação escolar, de adesão a um modelo compositivo a ser aplicado. Castro Rocha mostra o caráter produtivo e contrahegemônico da emulação, quando incorpora a obra lida e busca superá-la. Creio que as críticas machadianas de 1878 e 1879 ganhariam maior interesse se fossem lidas a partir daí, afinal, nesses anos, não se trata mais do jovem escritor, mas de um autor consolidado no campo literário, e que desenha um impasse, em que os estilos vigentes não são mais satisfatórios. Nesse sentido, poderia lançar outra hipótese, diversa de Castro Rocha, de que o crítico de 1878 ficaria pasmo com as Memórias póstumas, pois os traços acima elencados (caráter digressivo, valorização do acessório, erotismo...) derivam do caráter do narrador, de Brás Cubas. O discurso traduz e caracteriza o próprio narrador.

A linha de leitura acima apresentada deriva em grande parte do andamento do livro de Castro Rocha, pois, no capítulo 3, "Por uma poética da emulação", ele mostra que

De um lado, a reinvenção conscientemente anacrônica da aemulatio, em sua reciclagem pós-romântica, através da poética da emulação, provoca efeitos inesperados no plano da política cultural. $\mathrm{O}$ mais importante teria favorecido a superação da crise artística de Machado, uma vez que lhe permitiu compreender de forma inovadora o relacionamento de um escritor periférico com o modelo das "grandes nações pensantes". (p. 153)

Interessa destacar, então, a emulação como técnica artística que levaria Machado a deixar de lados padrões compositivos de seus primeiros romances. Quando cita Luciano de Samósata, mostra que esse autor fundamental para Machado obrigava o leitor a reconhecer as referências e os autores imitados, sob pena de ser incapaz de apreciar sua agudeza. Mais uma vez, o autor se coloca como leitor da tradição não para copiá-la mecanicamente, nem para reverenciá-la, mas para reescrevê-la em diálogo com o modelo. 
Depois de desenhar os traços principais da poética da emulação, Castro Rocha volta ao período decisivo do final dos anos 70, do século XIX, para mostrar os impasses próprios de Machado de Assis. 1878 foi um ano produtivo. Além de Iaiá Garcia, Machado escreveu crônica - o final das Histórias de 15 dias e, depois, de 30 dias, e a série de Notas semanais, em O Cruzeiro. Nesse mesmo jornal, vem sua "fantasia", "Na arca" e a crítica a Eça de Queiroz. Depois, em 1879, mais alguns textos a serem comentados. A explosão criativa aparece em março de 1880, na Revista Brasileira, com as Memórias póstumas.

Quando se volta para a forma da poética da emulação, Castro Rocha mostra o deslocamento da autoria para a leitura, para a posição necessária e produtiva do leitor. Atenta para necessidade de o leitor produzir o sentido da obra e para o modo como os narradores machadianos trazem para dentro da obra seu interlocutor. Como exemplo, Castro Rocha transita das Memórias póstumas a Esaú e Jacó. A partir da leituracolagem e da cópia criativa, Machado traz seus modelos para dentro de sua escrita e pede ao leitor que reconheça o ponto de partida bem como o desvio posto por ele. "Periférico, provinciano, não hegemônico: diferentes nomes para dizer o que Machado realmente é: leitor inventivo, copista original" (p. 330, grifo meu). Note o núcleo paradoxal da formulação "copista original", que traz o modo dessacralizador como Machado atualiza a tradição, devolvendo as obras consagradas ao uso comum de seus leitores.

Está aí no desenho da poética da emulação a grande novidade do livro de Castro Rocha. No retorno de Machado a padrões literários do século XVIII, um gesto anacrônico no século XIX, Castro Rocha desvela um procedimento, a emulação, como traço que explica a lógica compositiva de Machado de Assis. Lembra o gesto de Antonio Candido, e de outros críticos, que mostram o uso do anacronismo deliberado, bem como a importância da posição do Machado-leitor.

$\mathrm{Na}$ abertura dos capítulos, Castro Rocha coloca algumas citações que mostram o vínculo com a fortuna crítica machadiana. Mesmo assim, principalmente quando se desenha a poética da emulação, faz falta um cruzamento dessa nova perspectiva com outras leituras da virada machadiana, no sentido de recuperar os elementos dessa reação química em que o lançamento de O primo Basílio é visto como "evento-ponte", com 
"efeito catalisador". Na medida em que esses outros elementos não aparecem, parece que a crise machadiana se concentra na recepção do romance de Eça de Queiroz. Seria interessante considerar tanto O primo Basílio quanto seus leitores entusiasmados, pois eles representam parte da "nova geração", marcada pela aspiração ao Bem, à Justiça, que é fruto da influência da ciência, substituta da religião. Em 1879, Machado indica a falta de maturidade para se constituir um movimento literário autônomo, pois a origem da ideia nova é estrangeira. Assim, o interesse de Machado está em Eça, mas ultrapassao. Há o forte interesse pelo debate político, pela leitura da sociedade que se moderniza depois da Guerra do Paraguai. E há, principalmente, uma sociedade escravocrata e paternalista, que retarda e tenta impedir os esforços abolicionistas.

Nestas linhas, assaz sumárias, o interesse era apenas indicar que a emulação traz mais um ponto de vista para desenhar o retrato machadiano. Essa nova linha permite a compreensão de alguns procedimentos compositivos de Machado de Assis depois das Memórias póstumas, mas creio que ela ganha maior consistência quando o leitor cruza os achados de Castro Rocha com outros fatores, como o esforço de representação da realidade brasileira.

Antonio Marcos Vieira Sanseverino é professor adjunto de Literatura Brasileira do Departamento de Letras Clássicas e Vernáculas e do Programa de Pós-graduação em Letras da Universidade Federal do Rio Grande do Sul. Estudioso da crônica machadiana, é pesquisador do CNPq e atualmente coordena o projeto "Contaminação da forma: o conto, a crônica e a série Balas de estalo". E-mail: <amvsanseverino @ gmail.com>. 